\title{
Things Are Not So Bad. Presidential Address, American Pediatric Society, 1980 Annual Meeting, San Antonio, Texas
}

\author{
ALBERT DORFMAN \\ Departments of Pediatrics and Biochemistry: Joseph P. Kennedy Mental Retardation Research Center. Pritzker School \\ of Medicine, University of Chicago. Chicago. Illinois. USA
}

It is a great pleasure and an honor to appear before you as President of this society. The American Pediatric Society has counted among its membership most of the leading contributors to the health and well-being of children during this century. Included have been many of the pioneers of biomedical science.

Presidential addresses represent a challenge to the speaker and a trial to the audience. Such addresses can generally be classified as follows: (1) a review of great or not-so-great contributions to knowledge: (2) a discourse on how the world is going to hell in a hand basket: (3) a plea for a return to the good old days; and (4) how patients can be cured and great discoveries made with a pen knife and a package of matches.

I have decided to depart from these traditional approaches. To review my own scientific work would be an uncalled for selfindulgence and an unjustified imposition on a captive audience. I do not believe the world is going to hell in a hand basket. I do not believe the good old days were so good. I believe that modern technology has made vast contributions to both research and the practice of medicine.

With the sumptuous support and the prevailing expectations from biomedical research. it is not surprising that questioning and criticism have developed. Many of us have become inappropriately sensitive and defensive. a reaction not justified by the massive accomplishments of biomedical research.

Criticisms of biomedical research have appeared, some of which are not necessarily internally consistent. Three major issues have been raised: (1) because there is a great need for service, why should investment of money and manpower for research continue? Sufficient knowledge has accumulated which should now be applied: (2) despite the expenditure of vast amounts of money, cures for many afflictions of man have not been found; and (3) further research may result in discoveries which will be harmful to mankind.

I believe that these criticisms deserve serious consideration, but the fact that these questions have been raised should not automatically result in a change of direction of our efforts.

Before discussing these criticisms and their implications, it seems appropriate to examine the recent accomplishments of biomedical research. The growth of support of biomedical research in the post-World War II period has been phenomenal. Despite the fact that we are unhappy with current NIH budgets, it is remarkable that our society is willing to invest billions of dollars in this activity. The three factors that were probably of greatest importance in this development were the illness of Franklin Delano Roosevelt, the development of the atomic bomb, and the development of sputnik. Many far-sighted leaders, both scientists and lay people, seized the opportunities created by these events to develop long-term programs.

In 1956. I had an unusual chance meeting with the then ex-

Reyuests for reprints should be addressed to: Dr. Albert Dorfman. University of (hicago. Department of Pediatrics, 950) E. 59th St. (hicago. II. 60637 (USA)
President Harry Truman. When he learned of my occupation, he immediately turned the conversation to NIH grants. He stated that he felt that the initiation of this mechanism for support of medical research represented the most important accomplishment of his administration. I am inclined to agree. Hundreds of years from now when only a few historians will be able to define the Truman doctrine. biomedical discoveries supported by NIH grants will remain a precious heritage of man leading to the improved understanding of nature and the alleviation of human suffering.

The entire concept of federal grants for investigator-initiated research, awarded on the basis of peer review, represented a stroke of genius by the imaginative and devoted early administrators at NIH. Embodied in this concept is a unique partnership of government and private institutions. This most productive partnership in science in the United States is now coming under increasing threat by the rising power of lawyers and accountants. Cooperation between private institutions and government is diminishing, and an adversary relationship is growing. Vast sums and valuable effort are being diverted in a futile attempt to account for creative activity by methods more appropriate for the monitoring of manufacture of toilet tissue.

The revolution in knowledge of biology has resulted from the contributions of investigators of many nations, but a major part of the action has been centered in this country. Indeed some of the most important contributions made in other countries were supported by NIH. However, as witnessed by the vast waste of money in other federal programs, the availability of funds in and of itself is not sufficient to account for successful scientific discoveries. I would propose that American universities and medical schools were uniquely suited to utilize this support because of the existence of the Flexner model which recognized the essence of a scientific basis for medicine. The diversity of medical schools following this model permitted rapid and efficient expansion to utilize this flood of dollars to develop biomedical research.

Medical research was interpreted in the broadest sense. and the need for building an infrastructure of basic science knowledge was recognized. The development of the peer review system permitted a level of fairness and selection of excellence rarely equalled. Billions of dollars were handled with hardly the remotest suggestion of mismanagement of funds. Most important, however, biomedical research flowered to an extent undreamed of in previous times.

Review of the accomplishments of the biomedical establishment in the post-World War II period leads to the conclusion that not only are things not so bad, but indeed we may take pride in how good they are. The expenditure of money and effort has brought rewards beyond our wildest dreams. No longer can the disciplines of the basic sciences pertinent to medicine be separated. Instead, they join in a common body of knowledge involving both concepts and techniques. To attempt to summarize this progress in biology and medicine of the past 30 years is impossible, yet think of the things that have happened: the control of many virus diseases by 
immunization, the disappearance of rheumatic fever, the treatment of tuberculosis, the cure of many types of congenital heart disease, the improved treatment of diarrheal diseases, the advances in antibiotic therapy, the advances in the treatment of prematures. prenatal diagnosis, the control of hypertension. advances in transplantation of organs, and the development of cancer chemotherapy. Even this list is far from complete.

At a basic science level, the record is perhaps more impressive. The detailed comprehension of the nature of genetic information brings us to the brink of understanding of life itself. In the past few years, progress in unraveling the structure of the eukaryote genome has been breath-taking. This apparently highly theoretical approach is rapidly bringing practical dividends.

The commercial availability of human insulin. growth hormone. and interferon produced as a result of recombinant DNA technology is imminent. Improved methods of prenatal diagnosis based on the use of restriction enzyme technology have made the prenatal diagnosis of sickle cell anemia and thalassemia a reality. Indeed, reports in just the past few months suggest that gene therapy is a practical possibility. Rapid progress in understanding of the factors that control gene expression suggest that comprehension of the process of differentiation is a realistic goal. With this may come unexpected ways of preventing developmental defects. The application of new knowledge of molecular biology may be even more profound in agriculture with consequent implications for the food supply of the entire world.

My glowing progress report would seem to justify my title "Things Are Not So Bad." How do we make them better or at least keep them from getting worse? How do we answer the criticism that despite the expenditure of billions of dollars many serious diseases have not been conquered? Man has apparently been on the face of the earth for approximately two million years, and, civilization is perhaps twenty thousand years old, yet after only 30 years of serious support for biomedical research. some would expect all problems too be solved. At the same time, others (or sometimes the same individuals) would stop research to devote themselves to the application of existing knowledge. How ludicrous to assume that in 1980 we have reached an optimal state of understanding of biology and developed optimal methods for practice of medicine.

What then are the implications of these considerations for those of us charged with leadership of Departments of Pediatrics in the medical schools of our nation.

Despite overwhelming success of the biomedical research venture, it would be unrealistic to fail to recognize threats to the enterprise. Indeed, it is possible that a future discussion might be entitled "Nothing Fails Like Success."

First, the aim was to train more medical personnel. Now that we have tooled up for this purpose, it has been decided we will soon have too many. However. the most serious problem of all has been a growing dissatisfaction with the delivery of medical care. This dissatisfaction. partly based on real experience and partly based on unrealistic expectations, needs serious attention, but it cannot be rectified by a decrease in support for the intellectual content of medicine.

We as pediatricians are keenly conscious of the relatively poor standing of our country with respect to perinatal mortality. We flagellate ourselves and encourage others to flagellate us for this miserable showing. It has become commonplace for ambitious politicians and confused pseudoexperts to indict the biomedical community for failure to solve these problems.

I propose that these shameful conditions are in no way due to the failure of research but to serious social illnesses which afflict our society. The practice of medicine utilizes available fundamental knowledge, but the manner in which it is applied is a function of the social and economic mores of the society.

As physicians, particularly as pediatricians, we are appropriately keenly conscious of the effects of social and economic factors on health. Who cannot but be moved by the tragedies that are resulting from the explosive increase of teenage pregnancy. What a shock to our society has been the realization of the extent of child abuse recognized as a result of the work of our Howland Medalist, Henry Kempe. Attention to such problems by pediatric departments is appropriate and in the best tradition of the pioneers of our profession who were leaders in the early child welfare movements. In our concern with social and economic problems. however. we must remember that many others are trained and responsible for coping with these problems, but the medical schools of this country represent the primary resource for biomedical research and training.

A grave threat to the intellectual productivity of departments of pediatrics stems from the combination of demands for service and the attendant economic realities of medical practice.

Increasingly, deans of medical schools, departmental chairmen. and even section heads are becoming medical businessmen rather than intellectual leaders. Concern has been recently expressed for the rapid decline in the pool of physicians engaging in research. Indeed, this has become a favorite topic for presidential addresses. I share in this concern.

The loss of medically trained personnel to research is of great importance. Physicians entering a research career, be it in strictly clinical research or in basic science research, bring a special point of view rarely developed in Ph.D.'s. Our symposium speakers today who are outstanding molecular and cell biologists were all trained as physicians.

Although there is little doubt that economic factors play a major role in this decline, I believe other influences within medical schools are of critical importance. As medical school departments shift their emphasis from the scientific basis of medicine to the delivery of medical care, the model for young people changes. No longer are the intellectual leaders emulated but rather those who deliver service, particularly that which results in maximum remuneration. How much easier it is to balance a departmental budget by raising fees than by undergoing the struggle of formulating a really good research proposal that merits approval by a peer group of scientists. A vicious cycle develops. Departments must have larger staffs to do more service. Budgets must grow to pay the staffs, and more service must be performed to meet the budget. Specialties within medical schools and subspecialties within departments that are most lucrative irrespective of intellectual contribution prosper.

The number of subspecialties continues to multiply, and the length of training for each increases. Each subspecialty develops a series of techniques many of which quickly become the basis of lucrative practice in or out of academic medicine. Most pediatric fellowships are designed for subspecialty training, few for research. Therefore, in academic medicine, young people who have had a total of 25 years of education and training, none of which is concerned with research, are expected to enter into the difficult path of new discovery. No wonder most are frustrated at pursuing a career of investigation. Even the meager support for research training is rapidly disappearing as we fight the war against rise in oil prices by curtailing biomedical research and training.

I believe the momentum of biomedical research is now so great that despite these adverse factors, important discoveries will continue. Those of us assembled here who represent the leadership of departments of pediatrics must ask ourselves what roles our departments will play in this exciting adventure. In the past, pediatricians have been leaders in the fields of infectious diseases, metabolism, nutrition, cardiology, and genetics. Many important discoveries have come from laboratories of members of this society. Developmental biology, one of the most exciting areas of current investigation, is a root science for pediatrics. Will we become a group concerned only with the application of knowledge and the distribution of its benefits or will we be in the exciting forefront of discovery? Will we be content to worry only about the delivery of medical care or will we play our own role in the exciting discoveries to be made on prevention of diseases in children? How insignificant all of the efforts for treating poliomyelitis and rheumatic fever now appear when compared with the virtual eradication of these two scourges of childhood. Service is for now; research is forever! 
The desire for the understanding of nature represents an exciting human adventure. Some would contend that continuing exploration of nature is dangerous, and limits should be placed on the search for new knowledge. However, even if we were not concerned with alleviation of human suffering, man is a curious animal. Whereas changes in emphasis in educational programs or support will affect the rate of investigation, the genie is out of the bottle.

No people or government can control man’s curiosity. With this curiosity will come discoveries with resultant technology beyond our current dreams. It is possible that knowledge that stems from curiosity will destroy mankind. Perhaps the mutation which produced intelligence is indeed lethal. If so, there are more likely vehicles for man's demise than research in medicine and biology. I would prefer to believe that the mutation which produced intelligence will lead to continuing increase of wisdom, and the technology which results from curiosity will continue to enhance the quality of life. 